\title{
Assessing performance of directed functional connectivity measures in the presence of common source
}

\author{
Jisung Wang, Heonsoo Lee*, Seunghwan Kim \\ From 24th Annual Computational Neuroscience Meeting: CNS*2015 \\ Prague, Czech Republic. 18-23 July 2015
}

The mixing problem of electroencephalography (EEG) in the presence of common source could affect directed functional connectivity measures, resulting in an incorrect directionality of information flow between two signals. Here we introduce directed Weighted Phase Lag Index (dWPLI), a signed version of Weighted Phase Lag Index (WPLI) and compare this measure to Granger Causality (GC), Symbolic Transfer Entropy (STE), Phase Slope Index (PSI), and directed Phase Lag Index (dPLI) under common source effects. Robustness of the measures was tested in both analytic and simulating ways.
For the simulated time series, signals were generated from unidirectionally coupled autoregressive model and linearly mixed to achieve volume conduction and common noise effects.

As expected from the analytic calculation, dPLI and dWPLI were unaffected by the volume conduction while PSI, GC and STE were largely affected. (Figure 1A). The mean percentages of false identification were $14.00 \pm 7.66$, $22.35 \pm 4.78,27.38 \pm 7.04,1.99 \pm 1.36$, and $1.63 \pm 1.28$, for the GC, STE, PSI, dPLI, and dWPLI, respectively.

For the common noise case, only dPLI and dWPLI had their signs preserved. (Figure 1B). The mean percentages

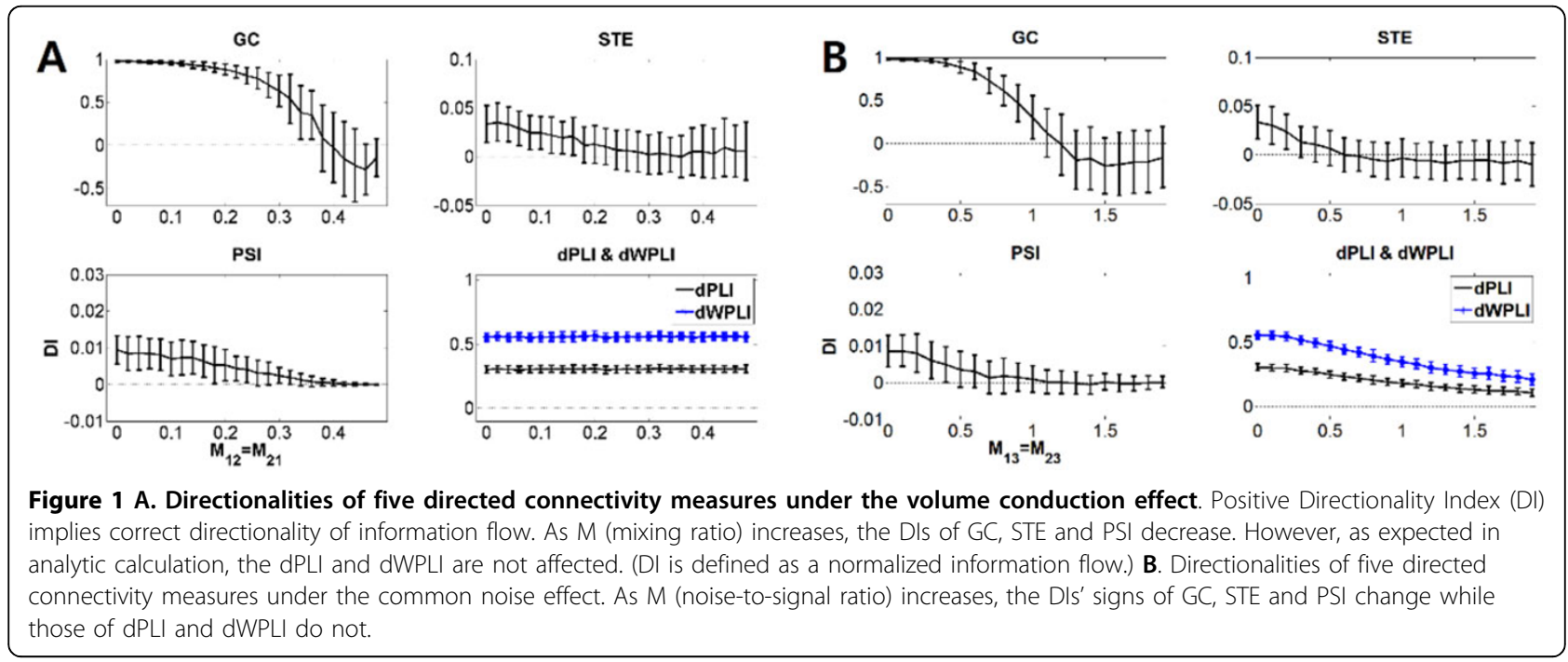

\footnotetext{
* Correspondence: beafool@postech.ac.kr

Physics Department, Pohang University of Science and Technology, Pohang,
} South Korea 
of false identification were $30.14 \pm 16.86,49.74 \pm 16.63$, $34.72 \pm 10.23,2.68 \pm 1.90$, and $2.34 \pm 1.55$.

Furthermore, the dWPLI outperformed dPLI for the common noise case $(\mathrm{p}<0.01$, Wilcoxon signed-rank test) which was also predicted from analytic calculation.

Present study shows the common source effects might lead to biased results with incorrect directionality of information flow. Among the five directed functional connectivity measures, dWPLI is much less affected by common source effects.

Published: 18 December 2015

doi:10.1186/1471-2202-16-S1-P124

Cite this article as: Wang et al:: Assessing performance of directed

functional connectivity measures in the presence of common source. BMC Neuroscience 2015 16(Suppl 1):P124.

Submit your next manuscript to BioMed Central and take full advantage of:

- Convenient online submission

- Thorough peer review

- No space constraints or color figure charges

- Immediate publication on acceptance

- Inclusion in PubMed, CAS, Scopus and Google Scholar

- Research which is freely available for redistribution

Submit your manuscript at www.biomedcentral.com/submit 